\title{
Cuerpos encriptados: entre el ser real e irreal
}

Daniela Ceccato *

\begin{abstract}
Resumen: Este ensayo aborda la temática del tratamiento del cuerpo en tres obras de Nicola Costantino: Peletería humana, Savon de corps y Trailer. Primero fue el body art en tomar al cuerpo como material de trabajo (entre los sesenta y los setenta del s. XX); después, en los noventa, hubo un retorno al cuerpo en el arte, haciendo referencia a su capacidad de ser objeto real y, a la vez, simbólico. Con las nuevas prácticas llevadas a cabo por los artistas, se introdujeron varios conceptos, como arte carnal (propuesto por Orlan), nueva carne y posthumanismo. Esta última concepción, por ejemplo, significa que la naturaleza del cuerpo humano -lo corpóreo- ha sido modificada. Entonces, ya no importa revisar qué hay debajo de la piel o buscar en el inconsciente (como en el body art), sino, explica Iván Mejías, "preguntar por las nuevas experiencias que modifican y esculpen el cuerpo, como la cosmética, los alimentos light, las cirugías estéticas...”. Así, los cuerpos son encriptados a través de distintas operatorias. El término encriptación proviene de la informática y significa el proceso que hace ilegible una información importante; y que puede leerse mediante una clave. El cuerpo es una materia significante y, como tal, cobra diferentes significaciones; aunque es el propio cuerpo, el cual porta la real “información” de sí.
\end{abstract}

Palabras clave: cuerpo en el arte - cuerpos encriptados - encriptación de los cuerpos materia significante - Nicola Costantino - posthumanismo.

[Resúmenes en inglés y portugués en las páginas 191-192]

${ }^{(*)}$ Periodista. Actualmente realizando la Maestría en Crítica y Difusión de las Artes (IUNA). Colaboradora periodística y correctora de estilo para medios gráficos -revistas especializadas, suplemento cultural y editoriales- y medios digitales.

\section{Nicola en su propia piel}

Nicola Costantino, una de las artistas más versátiles del ámbito artístico local e internacional, ha logrado en su trayectoria desarrollar varios saberes: primero, estudió bellas artes en su ciudad natal -Rosario-, especializándose en escultura; después, variadas técnicas para trabajarlas en sus obras. De adolescente aprendió a diseñar ropa-ayudó a su madre en su fábrica textil-, luego estudió la técnica del poliuretano expandido -siendo aprendiz 
de matricero en una fábrica de asientos de bicicletas-y la de resina poliéster -en un taller de cascos de moto-. Pasó por un laboratorio químico e hizo un curso de taxidermia, en el Museo de Ciencias Naturales de Rosario, donde aprendió el uso del formol, el alcohol y la glicerina. En 2006, se adentró en el universo de la fotografía. Y así, su habilidad pasa por embalsamar animales, diseñar ropa, carteras y zapatos -y hasta pelotas de fútbol- con silicona, incluso instalar la vidriera de una boutique, fabricar jabón con su propia grasa, crear máquinas ortopédicas para animales nonatos, mecanismos en hierro cromado con motores, realizar fotografías y videos. En todas sus obras deja de manifiesto su talento múltiple. No se aboca solo a un lenguaje artístico, sino que reúne varios para plasmar una idea; no se limita a un tema, a un concepto y tampoco a una sola materia significante: tanto los cuerpos de los animales como su propio cuerpo le sirven para posibilitar una nueva producción de sentido. Se puede afirmar que su labor artística remite a lo que el academicismo veía en el arte de la pintura, al cual consideraba contenido en dos valores: 1) en relación con valores espirituales -belleza, armonía, equilibrio, etc.- y 2) en relación con la perfección formal, en la que el artista es un virtuoso de la técnica.

Además, se la puede enmarcar dentro de lo que algunos autores, como Arthur Danto -entre otros- consideran arte contemporáneo o poshistórico. No se trata de la concepción que indica que es el arte creado durante la época en que se vive, sino al que es producido a partir de los años ochenta. Como explica Danto, desde los últimos veinticinco años hay una enorme productividad en las artes visuales "sin ninguna directriz especial que permita establecer exclusiones". Durante la década del sesenta, por ejemplo, se pudieron distinguir varios estilos (abstracción geométrica, pop art, minimalismo, arte povera, Nueva escultura, etc.), los cuales se sucedieron con rapidez; en cambio, los setenta, explica este autor, fue una época en la cual pareció que la historia había perdido el rumbo. Aunque cerca de los ochenta surgió el neoexpresionismo y la cosa pareció encarrilarse, enseguida el mundo del arte entró en una nebulosa inquietante. De forma definitiva, la contemporaneidad ha abierto una ventana. Como resumió Natalie Heinch: el arte contemporáneo es un movimiento de desplazamiento de las fronteras del arte; las cuales son, de modo indisociable, mentales y materiales. El límite entre lo moderno y lo contemporáneo está difuso. Mientras el cambio del arte premodernista al de la modernidad, según Clement Greenberg, pudo diferenciarse por el paso de la pintura mimética a la no mimética, el traspaso del arte moderno al contemporáneo se hizo invisible y, por ende, difícil de describir. Por esto, el término contemporáneo, para Danto, no logra definir con fuerza algo más que el arte que se hace en el presente y da lugar a la concepción de posmodernidad; aunque esta solo identificaría a un sector del arte contemporáneo y, por ende, prefiere denominarlo arte posthistórico. La poshistoria está definida por un período de enorme fertilidad artística, pero sin un eje estilístico que permita hacer clasificaciones. Hoy, hablar o definir un estilo resulta casi imposible; y tratar de encasillar a Costantino también.

En sus inicios, la artista se ocupó de lo "chancho", tanto en referencia al animal (a lo que se genera en rededor de él: en gastronomía, este se presenta en la mesa entero y, en lugar de dar asco, es devorado), como a la concepción que recibe el hacer el amor, considerado una chanchada (idea que Nicola ha mencionado en declaraciones respecto de su primera obra). Con su primera performance (realizada en 1993), Cochon sur canapé, manifestó el ritual que hay alrededor de la comida; los chanchos dispuestos se podían comer. Desde 
entonces, animales muertos se convirtieron en protagonistas de varias de sus obras, como: Chanchobolas (1998), Frisos (1999), Animal Motion Planet (2004), Esculturas animales (de 1992 a 1999) y Cajas (2000-2005), a los cuales exhibió embalsamados, envasados o calcados. De esta forma, se fue transformando en una de las artistas argentinas más cuestionadas -al conjugar en sus creaciones vida y muerte, refinamiento y grotesco-, pero también de las más talentosas. Nicola (que en realidad se llama Silvana, pero jamás se sintió como tal, según ella misma declaró) consigue pasar del concepto al hecho; no se queda solo en ideas, sino que las plasma en reales concreciones, en las que los detalles están cuidados al extremo. Una de las producciones con la cual tuvo una gran aceptación y así pudo acceder a la escena artística mundial fue Peletería humana, de 1996. Dos años más tarde se presentó con ella, al ser elegida la artista representante de Argentina, en la Bienal de San Pablo (Brasil) -cuyo tema fue: "antropofagia y canibalismo"- que le abrió las puertas para otras bienales y exhibiciones por el mundo. La obra se trató de una vidriera con veinte maniquíes que portaban vestidos, carteras y zapatos realizados con silicona simulando la piel humana (algunos vestidos, por ejemplo, tenían terminaciones en el cuello de pelo natural); todas piezas con estampados de estas partes del cuerpo: ombligo, ano y tetilla masculina. Para el año 2000, el MOMA aceptó para su colección el corsé de tetillas masculina. Su labor con silicona comenzó a mediados de la década del noventa, cuando después de su paso por el taller de Barracas, en Buenos Aires, se fue a Houston para un año de programa de artistas -Core Program-, donde empezó la producción de piel con este material. Se puede considerar a esta producción como una transición en su carrera: pasó de trabajar con el cuerpo animal a hacerlo (primero, conceptualmente) con el cuerpo humano; de modo más específico, la piel. En la instalación de la boutique de Peletería humana se perciben una vidriera (dividida en dos vidrios) y una puerta de entrada. Hay una especial iluminación en la vidriera donde están los productos -vestidos puestos en maniquíes sin cabeza y sin pies (solo el torso), carteras, un par de botas altas y zapatos en el piso- y en el vestidor que se ve detrás. Dentro de la boutique hay un perchero -realizado con caños, dos puestos en vertical y uno en horizontal- con los vestidos, dos maniquíes (iguales que los que están en la vidriera) -uno con un vestido y otro con un saco- y una silla alta detrás. Todo es color beige (parecido al tono de la piel humana): tanto los productos que se venden, como la cortina del vestidor, la silla y el piso -de parqué-.

Esta obra recrimina el extremo consumo de moda femenina. La colección tiene una ausencia de color (solo beige que simula ser el color de la piel) y remite a lo minimalista: hay una reducción a lo esencial. Estas piezas se convierten, de manera literal, en la segunda piel de la mujer. No obstante, esta colección, en vez de vestirla, busca desnudarla, pero en la piel del hombre. Porque es la tetilla masculina la textura predominante de las piezas, no los pezones. Es que la mirada machista sigue pesando en la sociedad, ¿es aún la que indica cómo se debe mostrar la mujer ante el otro? Entonces, en ese desvestir, la obra busca posicionarse como un regreso a lo básico; pero desnudarla, ¿ ¿de qué? ¿iDel consumo en extremo, tanto por el gasto excesivo como por la abundancia de productos adquiridos? ¿Despojarla de productos que se venden para esconder su esencia? ¿Sacarle de encima la mirada del hombre o potenciarla? La colección remite a la moda de lujo, tanto por sus cuidadosos detalles -en los que se percibe su notable manejo del couture-, como por las carteras que son imitación de dos modelos de la firma francesa Hermés. Estos productos son usados 
por mujeres de gran poder adquisitivo y social; de hecho, fueron realizadas por la casa en honor a dos celebridades: Jane Birkin, actriz y cantante, y Grace Kelly, actriz devenida en princesa de Mónaco. En la actualidad, el lujo se caracteriza por ser un estilo de vida en el que no hay que exagerar en el consumo, como tampoco sobrecargar la propia imagen que se muestra al mundo: menos es más, es el lema. ¿Y qué menos que solo mostrar la piel?

\section{Nicola y su grasa}

Después de esta obra, Costantino prosiguió trabajando con el cuerpo de animales muertos en las siguientes producciones hasta que, en 2004, con Savon de corps, inauguró una nueva forma de trabajo: emplear a su propio cuerpo como materia significante. Esta instalación, con la que generó un gran revuelo (otra vez se instaló la pregunta ¿es esto arte?, tanto por parte del público como por parte del universo artístico), está conformada por cien jabones realizados con su grasa -un 3\% de ella-, producto de una liposucción. Este producto, según especificó la artista, fue fabricado siguiendo las reglas de la cosmética de lujo: se utilizó el procedimiento industrial de estrusado, en una matriz confeccionada en exclusivo para esta obra. El jabón fue presentado a través de un video -donde la modelo, Nicola, está bañándose con su creación e invita al espectador a darse un baño con ella misma-, un backlight (elemento usado en publicidad) de gran tamaño con su imagen y el eslogan de la presentación del jabón, y el correspondiente packaging. En principio, se puede pensar que la obra remite a la cruel práctica realizada por el nazismo, que usó grasa de los cadáveres de personas judías para hacer jabones. Sin embargo, esta obra de Costantino pone de relieve el hecho, no solo de hacerse el cuerpo, gracias a la ayuda de la cirugía estética (práctica que tuvo gran auge en los noventa y principios del 2000), sino del reciclaje de uno mismo. La mujer del video, la propia artista, muestra su nuevo cuerpo (más delgado, pero con pronunciadas curvas), con una prenda pegada a este, en color beige (aunque tranparente, por lo que se funde con su piel), la cual se quita para tomarse un baño que, según su rostro, es sumamente placentero. Sumergida en una pequeña piscina, toma su jabón, que cuenta con parte de su propio cuerpo y, con gesto de disfrute, se lo pasa por su anatomía renovada. Un regodeo de Nicola por Nicola. Finalizado el baño, aparece este poema -inspirado en Le savon, de Francis Ponge- en primer plano, mientras la imagen de fondo, en movimiento, sobrevuela la superficie impoluta de esa tina:

Toma mi jabón, completamente desnudo, para volver tu agua afectuosa,/ circulará, te cubrirá de velos y huirá,/en una especie de agitación púdica./ La buscarás a tientas,/la encontrarás adelgazado, extenuado.../pero nunca perderá ese tres por ciento,/la esencia de Nicola... presencia indisoluta (Costantino, 2004). 
La artista no solo se deleita consigo misma, además quiere que los demás lo hagan. Es una suerte de diseminar su propio yo ante los demás: narcisismo puro.

El artista contemporáneo procede por selección, agregados y luego multiplicaciones: él o ella no buscan un estado ideal del Yo, del arte o de la sociedad, sino que organizan los signos para multiplicar una identidad por otra (...) El artista radicante inventa recorridos entre los signos: como semionauta, pone las formas en movimiento, inventa a través de ellas y con ellas trayectos por los que se elabora sujeto al mismo tiempo que constituye su corpus de obras (Bourriaud, 2009, pP. 57-59).

¿Cuál es el motivo por el que la artista desea compartirse con los demás? ¿O acaso quiere contagiar el placer de auto complacerse y de, finalmente, aceptarse tal cual se es? Hay, en definitiva, una concepción del placer del individuo con él mismo; de verse y sentirse bello, pero no aceptándose tal como es, sino sacando aquello que no gusta, aquello que se considera antiestético (en este caso, la grasa). ¿Hedonismo al extremo? Hedonismo que ponderó el universo de la moda, cuenta Gilles Lipovetsky (en El Imperio de lo Efímero. La Moda y su Destino en las Sociedades Modernas), porque esta disciplina, además de mostrar pertenencia de rango, nación, ha marcado una dirección de individualización narcisista "un instrumento de liberalización del culto estético del Yo en el seno mismo de una era aristocrática". En definitiva, remarca este autor, la moda estetizó e individualizó la vanidad humana, logrando hacer de lo superficial una finalidad de existencia. En plena transformación del mundo de la moda, no solo estética sino socialmente, esta ingresó en una nueva fase en la cual empezó a prevalecer la lógica individualista; por lo tanto, el vestido dejó de ser, cada vez menos, signo de honorabilidad social y pasó a importar una nueva relación con el otro, en la cual la seducción comenzó a destacar. Es por ello que cobra notoriedad no estar a la última moda, ni demostrar una superioridad social, sino concederse valor a uno mismo, agradar, sorprender, confundir y parecer joven, reflexiona Lipovetsky. Debido a la exaltación del look juvenil, todos tienen la posibilidad de modelar su propia imagen, de reciclarse. Savon de corps es un ejemplo mordaz de esta situación: primero pone en escena el reciclaje del cuerpo en pos de mostrar lo mejor de él (el sujeto se adapta a la nueva realidad: en caso de desear cambiar lo que no le gusta de sí, puede modificarse con una cirugía estética); segundo, el regodeo que siente la protagonista al pasarse el jabón que contiene su grasa, en una experiencia netamente narcisista (porque, además, invita al otro a bañarse con ella). El culto del cuerpo y el de la juventud (querer estar delgada no solo refleja el querer estar mejor en apariencia, sino el deseo de seguir siendo joven) está en su clímax. La época del look enaltece la singularidad, la teatralidad y la diferencia, remarca Lipovetsky y explica que se trata de cualidades que también se buscaron y ponderaron en épocas pasadas, pero de otra manera y dentro de límites más pequeños. En definitiva, explica este pensador, gracias al look, la moda rejuvenece; entonces se abre la posibilidad de jugar con lo efímero, brillar sin complejos en el éxtasis de la propia imagen inventada y renovada a gusto. Todo esto producto del placer que produce la super diferenciación individualista y el espectáculo artificialista de uno mismo ofrecido a la mirada del Otro. 
Mientras en la moda, el cuerpo fue tenido en cuenta desde sus inicios-sin cuerpo, no hay vestido-, el arte lo tomó en cuenta como material de trabajo (no como imagen, que estuvo presente desde los primeros tiempos), entre finales de los sesenta y los setenta del siglo $\mathrm{XX}$, a través del body art (derivado del arte conceptual). Esta corriente artística "sintoniza históricamente con el redescubrimiento del cuerpo por las investigaciones psicoanalistas y el capitalismo monopolista", remarca Iván Mejía en El cuerpo posthumano en el arte y la cultura contemporánea. Los artistas de esta vertiente, precursores del performance, consideraban usar su cuerpo para realizar una obra escultórica o pictórica, más que teatral. Según el crítico francés François Pluchart, el body art buscaba producir "un lenguaje inédito, no codificado que, rechazando la historia, el sentido y la razón, sea capaz hablar del cuerpo, aquí y ahora, con el fin de preparar también el mañana”. En la década del noventa del siglo pasado, algunos artistas -entre ellos, Nicola Costantino- hicieron un retorno al cuerpo como materia de trabajo, teniendo como referencia al body art. Este retorno al cuerpo tiene una connotación abstracta: ya no importa su realidad, sino su apariencia; pero también su capacidad de ser objeto real y, a la vez, simbólico. Según Mejías, en el arte, en esos años, se introdujo el tema del posthumanismo, concepto empleado en el Manifiesto para cyborgs de Donna Haraway (1985) y que refiere a que la naturaleza del cuerpo humano -lo corpóreo, lo orgánico del hombre- ha sido modificada. Entonces, a los artistas poshumanistas ya no les importa revisar qué hay debajo de la piel o buscar en el inconsciente,

sino preguntar por las nuevas experiencias que modifican y esculpen el cuerpo, como la cosmética, los alimentos light, las cirugías estéticas o de cambio de sexo, hasta la manipulación genética, la clonación y la superación del cuerpo por medio de computadoras y otras prácticas que suponen una manera contemporánea de habitar el mundo. Se trata (...) de presentar y representar un momento de apresurados cambios tecno-científicos utilizando el cuerpo como soporte para intervenciones artificiales y como objeto a modificar ara el desarrollo de la ciencia (Mejías, 2005, p. 40).

Otro concepto que explica el uso del cuerpo en el arte como objeto, desde la década del noventa en adelante, es el de nueva carne, adoptado por José Navarro (en su libro, La Nueva Carne: una estética perversa del cuerpo, 2002) de la película Videodrome (1982, del cineasta canadiense David Cronenberg), en cuyo final aparece esta frase: Long live the NewFlesh" (Larga vida a la Nueva Carne). Esta concepción sostiene que el cuerpo humano se lleva al extremo; se trata de transformar al cuerpo en uno nuevo tomando como base el cuerpo existente. Se consideran dentro de esta práctica, además de al body art, a Orlan, Stelarc, Cindy Sherman, Jan Saudek, entre otros. Una de las prácticas tenidas en cuenta por la nueva carne son las cirugías estéticas (por ejemplo, Orlan fue la primera en adoptarlas en su obra): 
Las operaciones de cirugía estética alteran la carne humana, retocando y transformando el cuerpo, agrediendo contra su naturaleza. El hombre, en su afán de mejorar, de perdurar más y mejor y de disponer de mayores comodidades en la vida social y doméstica, se lanza en esta carrera sin freno en busca de una nueva raza, en la que la unión de hombre y máquinas es real y palpable (Navarro, 2002, p. 359).

Fue en los años noventa cuando Orlan se convirtió en la primera artista que utilizó la cirugía estética en una performance. Ella misma explicó su labor:

Somos una generación que tomamos la palabra para reivindicar nuestro cuerpo. Nos planteamos si ser o no ser madres. ¡Gracias a la píldora, la píldora...! Había una época en que no casarse y no tener hijos era un acto político bastante violento. Siempre lo más difícil de soportar es que una mujer haga lo que quiera con su cuerpo, no lo que se espera que debería hacer. Queremos tener un cuerpo y poder gozar de él más allá de lo que nos enseñan. La idea es salirse del marco, ejercer el libre albedrío para inventarse y realizar una escultura de sí mismo. Propongo un cuerpo desacralizado, disidente, que 'decorpora' y puede ser decorado (...) Me rebelé contra los dictados de la ideología dominante. Creo que la identidad es mutante, movediza, nómade. Las imágenes se multiplican: una imagen produce otra imagen. Me operé para esculpirme a mí misma, para producirme y producir una obra. Produje dibujos con mi sangre, dirigí la fotografía y el video durante mis operaciones. Algunas se transmitieron vía satélite. Cada 'Operación-Performance-Quirúrgica' es una 'Operación-Ópera' (Trosman, 2006).

A su vez, esta artista creó un nuevo concepto, el de arte carnal y escribió su manifiesto, cuya definición es:

El Arte Carnal es un trabajo de autorretrato en el sentido clásico, pero con los medios tecnológicos, que son los propios de su tiempo. Oscila entre la desfiguración y la refiguración. Se inscribe en la carne. Porque nuestra época comienza a ofrecer la posibilidad de realizarlo. El cuerpo deviene un ready-made modificado pues ya no es el ready-made ideal que basta con firmar (Trosman, 2006).

Este breve recorrido respecto del tratamiento realizado al cuerpo en el arte (como materia de trabajo), plantea las bases para el siguiente desarrollo: “¿Por qué yo soy una obra de arte?”. Este cuestionamiento se lo hizo la filosofía en el momento en que cualquier cosa empezó a ser considerada arte e hizo difícil explicar el límite entre lo moderno y lo contemporáneo, según explicó Danto (en Después del fin del arte). Esta idea, a su vez, coincide con el concepto de radicante, lo cual. 
implica un sujeto: pero este no se reduce a una identidad estable y cerrada sobre sí misma (...) es el movimiento lo que permite la constitución de una identidad (...) El sujeto radicante se presenta como una construcción, un montaje: dicho de otro modo, una obra, nacida de una negociación infinita (Bourriaud, 2009, pp. 61-62).

\section{Nicola por dos}

En su obra Trailer, Costantino se vuelve a preguntar ¿por qué yo soy una obra de arte?; controversia que surgió en Savon de corps y que en las siguientes producciones en las cuales ella se ha convertido en protagonista (no solo con el uso de su cuerpo, sino con su imagen en primer plano), la artista busca responder. En este caso, se inmiscuye en la creación de su doble e instala el tema de la clonación (una de las temáticas del posthumanismo). En esta producción, la artista va más allá de sí misma como materia significante para duplicarse. Sí, redobla la apuesta y, literalmente, Nicola hace a Nicola. En este trabajo confluyen varios lenguajes que con maestría supo congeniar: el video, el cual, con un sutil suspenso -a lo Hitchcock, remarca la propia Costantino- la muestra a ella actuando, la fotografía, las artes plásticas y hasta el diseño de moda. Esta instalación, presentada en 2010 en Fundación YPF, remite a dos acepciones del término trailer: avances de un filme y vehículos que se usan en pleno rodaje de un largometraje. Y ambos significados refieren a este trabajo artístico multifacético. Pero hay un elemento aún más atrayente-conceptual, pero materializado- que viene de la psicología: el doble, como ella misma lo menciona, doppelgänger. De forma literal, ella se hace a sí misma: no solo en los sentidos filosófico, psicológico o espiritual (en lo personal, no es Nicola, sino Silvana), sino en lo material. Nicola hace a Nicola. ¿Quién es quién? Aunque el espectador puede en principio confundirse, el video -con aire misterioso y sumamente atrapante- muestra el paso a paso de la fabricación. La obra está conformada por cinco trailers y cada uno ofrece distintos escenarios: el taller de la artista, uno de diseño de moda, la habitación de su bebé, otro en el que está diseminado el principal personaje de la obra y un quinto en donde se proyecta Trailer. Además, se suman los carteles de la -supuesta- película que tiene el mismo nombre que la producción en su conjunto.

El doble creado por Costantino, cual Franskestein, plasma lo oscuro de su ser, lo que ha intentado ocultar y que ahora se le revela en persona. Según Freud, en su texto "Das Unheimliche" ("Lo siniestro", 1919; en el cual analizó el cuento "El hombre de arena" de E.T.A. Hoffmann), el doble es lo ominoso -la artista lo menciona en el catálogo realizado para la exposición de esta obra-, es decir, lo extraño. Su presencia podría funcionar como un permanente retorno de lo igual. Asimismo, expresa que el doble es una representación que nace 
sobre el terreno del irrestricto amor por sí mismo, el narcisismo primario, que gobierna la vida anímica tanto del niño como del primitivo; con la superación de esta fase cambia el signo del doble: de un seguro de supervivencia, pasa a ser el ominoso o anunciador de la muerte (Freud, 1919).

Lo curioso es que Nicola hace resurgir a su doble en cuanto se entera, felizmente, de que está embarazada. En ese proceso de gestación, da vida por dos. Con la técnica del vaciado crea a la Nicola artefacta (así la llama), la cual, con una expresión seria y como apenada, por momentos parece una especie de ángel de la guarda que protege a la verdadera mujer $y$, por otros, un ente malvado que busca pervertir las emociones más profundas de su ser creador. Sus enormes ojos (la marca fisonómica de la artista) permanecen abiertos; pareciera que no quieren perderse de nada. Funcionan como un subconsciente siempre despierto. Durante nueve meses y hasta después del nacimiento del hijo, la Nicola artefacta acompaña a la real. Pero, de compañera pasa a convertirse en una amenaza. Hasta que Nicola destruye a Nicola. Sin dañarse, hace añicos esa parte nefasta de sí que no desea más. Trailer pone de manifiesto un pensamiento que, en realidad, abruma a todo ser humano en algún momento de la vida: ¿quién soy en realidad? En toda esta producción, para la cual no alcanzan los ojos para percibir todo lo que Costantino significa de sí misma, la búsqueda para hallar una respuesta es infinita. A esta dispersión-término propuesto por Seth Price para la práctica artística que consiste en "diseminar información en distintos formatos"- se añade una propagación de acciones. En poco más de tres minutos que dura esta película inconclusa -que queda solo en avances-, se ve a Nicola en plena actividad: primero como actriz, después como escultora, fabricándose en su taller (la creación de su autómata requiere de una labor escultórica, incluso de tareas dignas de la tanatoestética: la práctica de conservación y embalsamiento de cadáveres), como diseñadora -cosiendo un vestido a su doble-, como fotógrafa... A lo que se suma la enorme información de su obra: en distintas escenas aparecen el jabón, los Frisos, los Chanchobolas, los retazos de los vestidos de piel de siliconas. Como se dijo, en un universo posmoderno todo vale, pero en un universo radicante, "los principios se mezclan y se multiplican por combinatorias: ya no hay sustracción sino multiplicaciones incesantes", sintetiza Bourriaud. Ella, ella y ella: Nicola, su obra y su doble.

Para este autor francés, al individuo hoy le resulta complicado fundar su identidad en un terreno estable y esta problemática invita a una comunidad proveedora de identidad o, por el contrario, a un constructivismo puro. El adjetivo radicante, continúa, califica al sujeto contemporáneo, "atormentado entre la necesidad de un vínculo con su entorno y las fuerzas del desarraigo, entre la globalización y la singularidad, entre la identidad y el aprendizaje del otro. Define al sujeto como un objeto de negociaciones" (Bourriaud, 2009, p. 57). Por lo tanto, el artista contemporáneo "procede por selección, agregados y luego multiplicaciones: él o ella no buscan un estado ideal del Yo, del arte o de la sociedad, sino que organizan los signos para multiplicar una identidad por otra" (Bourriaud, 2009, p. 57). El radicante, prosigue Bourriaud, se pone en camino y no tiene espacio adonde volver, ya que en su universo no existe ni origen ni fin, con excepción de los que se ponga él mismo: "Se puede llevar consigo fragmentos de identidad, a condición de que se 
los trasplante en otros suelos y que se acepte su permanente metamorfosis" (Bourriaud, 2009, p. 58). Nicola Costantino se metamorfea, se transforma a sí misma y se multiplica, ¿cómo? En vestidos, carteras y zapatos con su piel, en jabones de lujo con parte de sí misma su grasa y creando a su doble. Por un lado, propone el quedarse solo con la propia piel; porque, en definitiva, es ella la única que puede decirnos quiénes somos en realidad, no lo que llevemos puesto. Asimismo, plantea la idea de una belleza reciclable: de lo feo, desechable (la grasa corporal), surge lo bello (un producto de limpieza); se pondera la belleza corporal, pero también se busca llegar a la belleza interior (que refleja la real identidad), la cual se obtiene cuando el individuo está conforme consigo mismo. Por otro lado, da la posibilidad de crearse desde cero a sí mismo; ser igual, pero distinto, mejorado. Aunque la esencia de uno no se modifica; de hecho, en la obra, la protagonista termina por destruir a su doble.

\section{Cuerpos encriptados}

Puede considerarse que la producción artística realizada por Nicola Costantino con su propio cuerpo, incluida la obra en la que trabaja con la piel humana (simulada con silicona), es de encriptación. La misma labor que hace el sujeto de la contemporaneidad ayudado por la moda (y la medicina estética) quien, convertido en objeto, no hace más que modelar su imagen exterior, aunque difiera de lo que siente en su interior. El término encriptación, que proviene de la informática, significa el proceso que hace ilegible una información importante; esta, una vez encriptada, puede leerse mediante una clave. Este vocablo tiene relación con el de criptografía que se trata del arte de escribir con clave secreta. La historia de la criptografía remite al objetivo de esconder la real información para que no fuera descubierta por quien no correspondiera (en especial, en períodos de guerra). Más allá de la metodología usada por la critptografía o la encriptación, proveniente de la matemática, en este caso el uso del término es metafórico y sirve para explicar que el cuerpo de la artista, en sus propias obras, es encriptado bajo distintas operatorias.

La relación con la información no es más que la misma en una lógica semiótica y una lógica informática. En el campo de la informática, la información, objeto a tratar, es susceptible de ser sometido a operaciones, es un real medible, cuantificable, operatorio y nacido de una casualidad hecha por sí misma de una sucesión de operaciones. En cambio, en el campo de la semiótica, la información es una forma simbólica intepretable, vinculada a una lógica arbitraria, y es sometida a una actividad lingüística que escapa a la casualidad, ya que depende de elecciones asumidas por un sujeto al curso de un proceso simbólico de comunicación y de mediación. La semiótica de la información es el conjunto de procedimientos y de procesos 
por los cuales la información se inscribe en una lógica interpretable. Es la memoria la que, en semiótica como en informática, permite reconocer la información operatoria por conservarse y la información inútil (el "ruido")... (Lamizet, 2004, p. 1).

El cuerpo es una materia significante y, como tal, al estar a disposición de la mirada ajena, cobra diferentes significaciones; aunque es el propio cuerpo, el cual porta la real "información" de sí. Es interesante la relación que establece Susana Saulquin, en La muerte de la moda, el día después, entre vestido, cuerpo e individuo (teniendo en cuenta que muchos estudios de la moda y el vestir separan el vestido del cuerpo), para comprender la función del cuerpo -respecto de la moda- a través de los años:

... Sin considerar para nada la confortabilidad o el bienestar de las personas, el vestido de moda indicaba sus privilegios con respecto al cuerpo, que sofocado y minimizado sólo le servía de soporte (...) ese cuerpo soporte ha debido adaptarse a las estrategias de la cultura de masas. Desterrada su propia topología tuvo que aplanarse, homogeneizarse, adelgazar hasta asexuarse porque su única función era conformar con el vestido masivo, la imagen exigida por la sociedad (...) El cuerpo democratizado, standarizado, homogeneizado y simplificado en sus formas (Morin, 1966, p. 46),

resulta además un cuerpo fragmentado (...) Como tal comparte con el mundo que lo rodea su misma estructura molecular, puede equilibrar crecimiento con desgaste metabólico y conformación de ciertas características específicas como fuerza o debilidad. Al actuar la naturaleza o la técnica sobre esa materia prima, consciente o inconscientemente, se produce el cuerpo estético, el cuerpo sano o enfermo, el deportivo o intelectual, el gordo o delgado, el de raza negra o blanca. Además de utilizarse como instrumento de placer, de seducción, de autodestrucción, de violencia, permite el señalamiento de los estados de ánimo. Visible para los otros puede muy bien conformar a partir de sus fragmentos con el vestido, una unidad que actúe como máscara, y que nada tenga que ver con lo que el cuerpo sienta de sí mismo (Saulquin, 2010, pp. 168-169).

Esta última oración simplifica lo de la encriptación de los cuerpos. Porque lo que siente el cuerpo, verdaderamente, no es lo que le muestra al otro. La información se oculta.

Para Merleau-Ponty, el grande y paradójico enigma es que el cuerpo es a la vez vidente y visible para los otros. Aquel que mira todas las cosas que lo rodean, que se convierten como sus prolongaciones, en parte de sí, también puede mirarse a sí mismo viendo (en un espejo, por ejemplo). Es, además de visible, sensible para sí mismo (Saulquin, 2010, p. 169). 
Prosiguiendo con el desarrollo de la socióloga de moda, esta destaca que el cuerpo, además de acatar los mandatos sociales, cuenta en sus huellas su propia historia.

Rastros de vida que la posmodernidad va a enmascarar, para enfatizar los discursos de poder consecuentes con una cultura de la imagen. Multiplicidad de máscaras que, al simular identidades, impulsan a descreer de los aspectos formales. Si a partir de entonces las formas, a través de las cuales se expresan determinados propósitos, se tornan inciertas y no verdaderas, tal vez solo resta especular sobre la naturaleza de esas intenciones. ¿Y el cuerpo real? La posmodernidad trasladó su fragmentada percepción del mundo a la visión mercantilista de un cuerpo de múltiples servicios a cumplir. A diferencia del cuerpo clásico, el posmoderno es enteramente permeable a funciones y mandatos exteriores. Abierto, público, desbordado, fragmentado y por lo tanto inexpresivo, le disputa cada vez má al vestido la primacía, por saber representar la sumisión con mayor dramatismo (S. Saulquin, 2010, p. 178).

Por otro lado, es válido el aporte realizado por Bryan Turner, en El cuerpo y la sociedad, en el cual desarrolla una teoría de la sociología del cuerpo: “...Los seres humanos, tienen cuerpos y son cuerpos. De forma más clara, los seres humanos están corporizados justo en la medida en que están dotados de entidad” (Turner, 1989, p. 25). Además, señala que el cuerpo es la experiencia más inmediata del ser humano, "omnipresente de la realidad y de su solidez", pero, a la vez, puede ser subjetivamente elusivo. Prosigue el autor con la idea de que el cuerpo es "un sitio, un instrumento, un entorno, una singularidad y una multiplicidad" y afirma que estamos en un mundo en el que los cuerpos están sujetos a inspección y vigilancia por parte de las instituciones profesionales, ocupacionales y gubernamentales. Como señala Saulquin, la presión que ejerce la sociedad para moldear al cuerpo en su beneficio tiene resultados diversos.

Con el máximo poder instalado en el segmento de la juventud y en la idealización del cuerpo, se genera el narcisismo del yo como verdadero objeto de culto a partir de gimnasias, estéticas reparadoras, rigurosos regímenes y largas jornadas deportivas. Como la relación que cada persona tiene con su propio cuerpo reproduce la relación que tiene con su ámbito social, se multiplica la masiva sumisión (Saulquin, 2010, p. 181).

Por lo tanto, el cuerpo sometido no es más que un cuerpo encriptado. Lo que realmente siente, poco tiene que ver con lo que muestra al otro. Nicola Costantino, quien ha sabido hacer una lectura crítica de la realidad circundante (en referencia a lo que vive sujeto de la contemporaneidad), no hace más que encriptar su propio cuerpo para imprimirle diferentes producciones de sentido. A consecuencia, el ser real y el irreal no hacen más que fundirse hasta confundir, al propio sujeto y a los demás; y así, la pregunta ¿quién soy en realidad? ingresa en la mecánica del eterno retorno: vuelve, una y otra vez, a los orígenes del ser para poder responder. 


\section{Referecias Bibliográficas}

Aumont, J. (1992). La imagen. Barcelona: Paidós.

Bourriaud, N. (2009). Radicante. Buenos Aires: Adriana Hidalgo Editora.

Danto, A. (2003). Después del fin del arte: el arte contemporáneo y el linde de la historia. Barcelona: Paidós.

Estañol, B. El doble, texto publicado en Revista de la Universidad de México. Disponible en: www.revistadelauniversidad.unam.mx/6509/pdfs/65estanol.pdf. Consultado en agosto de 2011.

Heinch, N. (1998). Las fronteras del arte contemporáneo: entre esencialismo y constructivismo, texto presentado en el Coloquio "Las fronteras estéticas del arte", Université ParisLyon VIII, y publicado en Les Frontierés esthétiqus de l'art, París, L’harmattan, 1999.

Lamizet, B. (2004). Semiótica de la lectura. Texto original del francés Sémiotique de la Lecture. Traducción de Susana Arroyo-Furphy. Disponible en: www.razonypalabra.org.mx/ anteriores/n38/blamizet.html

Lipovetsky, G. (1987). El Imperio de lo Efímero. La Moda y su Destino en las Sociedades Modernas. España: editorial Anagrama.

Mejía, I. (2005). El cuerpo posthumano en el arte y la cultura contemporánea. México: Coordinación de publicaciones ENAP-UNAM.

Navarro, J. (2002). La Nueva Carne: una estética perversa del cuerpo. Madrid: Valdemar.

Prada, J. M. (2001). La apropiación posmoderna: arte, práctica apropiacionista y teoría de la posmodernidad. Madrid: Ed. Fundamentos.

Saulquin, S. (2010). La muerte de la moda, el día después. Buenos Aires: Paidós.

Trosman, C. (2006). Orlan: El Arte Carnal y la ruptura del concepto social de cuerpo. Disponible en: www.topia.com.ar/articulos/orlan-el-arte-carnal-y-la-ruptura-del-concepto-social-de-cuerpo

Summary: This paper addresses the issue of the treatment of the body in three works of Nicola Costantino: Peletería Humana, Savon de corps and Trailer. Body Art was the first in taking the body as a working material (from the sixties and seventies in the 20th century). Later, in the nineties, there was a return to the body in art, referring to his ability to be a real object and, at the same time a symbolic one. With new practices carried out by the artists, several concepts, as carnal art (proposed by Orlan), new meat and posthumanism were introduced. This latter view means that the human body nature -the corporeal- has been changed. From this vision, is no necessary to scan under the skin or in the unconscious (as in body art) but, after Ivan Mejias, "ask about the new experiences that modify and sculpt the body, such as cosmetics, light food, cosmetic surgery ... ". Thus, the bodies are encrypted through different operations. The encryption term comes from computing and means the process to transform important information in unreadable information which has to be decoded by a password. The body is a significant matter and takes different meanings; although it is the body itself, which carries it real "information" of itself. 
Keywords: body encryptation - body in art - encrypted bodies - Nicola Constantino- posthumanism - significant matter.

Resumo: Este ensaio procura interferir no tratamento do corpo em três obras de Nicola Costantino: Peleteria Humana, Savon de Corps e Trailer. Primeiro foi a arte do corpo de tomar o corpo como material de trabalho (a partir dos anos sessenta e setenta do XX s.) mais tarde, na década de noventa, houve um retorno ao corpo na arte, referindo-se a sua capacidade de ser objeto real e, ao mesmo tempo simbólico. Com novas práticas realizadas pelos artistas, foram introduzidos vários conceitos, como arte carnal (proposto por Orlan), carne nova e pós-humanismo. Este último ponto de vista, por exemplo, significa que a natureza do corpo humano, o corpóreo, foi alterada. Portanto, não importa o que está embaixo da pele ou olhar no inconsciente (como no arte do corpo), senão como explica Ivan Mejias, "perguntar sobre as novas experiências que modificam e esculpem o corpo, tais como cosméticos, alimentos llight, as cirurgias estéticas ... “. Assim, os corpos são criptografados através de diferentes operações. O termo vem da informática e significa o processo que faz ilegível uma informação importante, que pode ler-se mediante uma chave. O corpo é uma matéria significante e como tal tem diferentes significados, embora seja o próprio corpo, que leva a "informação" real.

Palavras chave: corpo na arte - corpos criptografados - matéria significante - Nicola Constantino - pôs-humanismo. 